\title{
Effects of Smoking on ADPKD: Frequency of Vascular Events and Concentrations of Soluble CD40 Ligand
}

\author{
Jason S Brody, Wei Wang, Robert W Schrier and Berenice Reed-Gitomer ${ }^{*}$
}

Division of Renal Diseases and Hypertension, Department of Medicine, University of Colorado Anschutz Medical Campus, Aurora, USA

*Corresponding author: Berenice Reed-Gitomer Ph.D, Division of Renal Diseases and Hypertension, Dept. Medicine, University of Colorado Anschutz Medical Campus, Bldg. 500, Rm C5000B, Mail Stop C28, 13001 E. 17th Place, Aurora, CO 80025, USA, Tel: 303 724 1685 ; Fax: 303 724 1683; E-mail: Berenice.Gitomer@UCDenver.edu

Rec date: Dec 19, 2014 Acc date: April 03, 2015 Pub date: April 07, 2015

Copyright: (C) 2015 Brody JS, et al. This is an open-access article distributed under the terms of the Creative Commons Attribution License, which permits unrestricted use, distribution, and reproduction in any medium, provided the original author and source are credited.

\begin{abstract}
Background: Cardiovascular disease is the leading cause of death among patients with autosomal dominant polycystic kidney disease (ADPKD). Smoking increases inflammation and contributes to cardiovascular disease in the general population. The purpose of this study was to determine the effects of smoking on health outcomes in patients with ADPKD.
\end{abstract}

Methods: The study population included 350 smoking and 371 non-smoking ADPKD patients who participated in studies at the University of Colorado between 1985 and 2001. In addition, outcome data collected between 2011 and 2012 by survey from 159 smoking and 259 non-smoking ADPKD patients was analyzed. The frequency of cardiovascular or cerebrovascular events, age at onset of end stage renal disease, and serum and urine chemistries where available were compared in smoking and non-smoking patients. Serum levels of soluble CD40 ligand measured by ELISA were analyzed in a sub-set of 40 patients matched by age, sex, and renal function.

Results: ADPKD smokers from the University of Colorado study cohort had more cardiovascular events and higher urinary protein excretion than ADPKD non-smokers. The ADPKD survey respondents had a higher rate of cerebrovascular events in patients who smoked. Smoking years were associated with increased odds of having a cerebrovascular event. Serum soluble CD40 ligand level was higher in ADPKD patients who smoked compared to non-smoking patients ( $5293 \pm 3168$ vs. $3285 \pm 2169 \mathrm{pg} / \mathrm{mL}, \mathrm{P}=0.025)$ indicative of increased inflammation.

Conclusions: ADPKD patients who smoke have a higher hazard for cardiovascular and cerebrovascular events and evidence for increased inflammation.

Keywords: ADPKD; Smoking; sCD40 ligand; Proteinuria; Cardiovascular disease; Cerebrovascular disease

\section{Introduction}

Autosomal Dominant Polycystic Kidney Disease (ADPKD) is a potentially lethal, heritable disorder that affects approximately 600,000 Americans [1]. The disease is characterized by the presence of multiple renal cysts originating from the tubular epithelial cells [1]. The rate of progression to renal failure in ADPKD is variable between affected individuals and this has been attributed to the combined effects of gene mutation (PKD1 vs. PKD2), modifier genes, epigenetics and the environment [2-4]. A high prevalence of cardiovascular risk factors and events in ADPKD patients contributes to increased mortality risk [5]. Since 1975, when renal replacement therapies were introduced, cardiovascular complications have been the leading cause of death among patients with ADPKD [6].

Despite well-publicized evidence proving that cigarette smoking has harmful effects on human health [7], the Center for Disease Control (CDC) estimates that in 2012, 42.1 million adults in the United States were current smokers, 33 million of whom were daily smokers (http:// www.cdc.gov/tobacco/campaign/tips/resources/data/cigarettesmoking-in-united-states.html). While environmental factors have been shown to contribute to smoking initiation, genetic factors may influence liability to nicotine dependence [8]. Studies with monozygotic and dizygotic twins have also demonstrated that sensitivity to second-hand smoke exposure is moderately heritable $[9,10]$. Cigarette smoking contributes to pro-inflammatory responses, cardiovascular disease, cerebrovascular disease, and higher levels of proteinuria in the general population [11-15]. Proteinuria is not a common complication among ADPKD patients. However, when present proteinuria levels are associated with more rapid progression towards renal failure [16]. Moreover, patients with ADPKD are at an increased risk for bronchiectasis and a recent study noted a significant correlation between radiologic bronchiectasis and smoking in ADPKD [17]. Evidence shows that smoking is linked to higher levels of soluble CD40 ligand (sCD40L) a marker of inflammation [18]. Concentrations of sCD40L were previously shown to be higher in patients with acute myocardial infarction indicating a link with cardiovascular events [18]. At a molecular level cigarette smoking has been shown to induce epigenetic changes. In a recent study cigarette smoking reduced DNA methylation at several genomic loci which may contribute to smoking associated health risks [19]. Significantly, in this previous study the effect of smoking on DNA methylation was partially reversible on smoking cessation [19]. 
Page 2 of 6

There is no question as to whether ADPKD or cigarette smoking independently cause harm to human health, but the main study reflected in this paper intends to elucidate the particular risks inherent to cigarette smoking in ADPKD patients. Separate studies show that both cigarette smoking and ADPKD elicit a pro-inflammatory response $[20,21]$, so this report aims to investigate and determine whether or not the effects of cigarette smoking exacerbate inflammation in ADPKD.

The hypothesis motivating this research study is that current cigarette smoking enhances the pro-inflammatory response in ADPKD thereby enhancing cardiovascular and renal damage in affected patients with ADPKD.

\section{Materials and Methods}

\section{Study populations}

All patients provided informed consent to the protocol, which was approved by the Institutional Review Board. To investigate the effects of cigarette smoking in ADPKD, three separate analyses were conducted on independent data sets. Two populations of ADPKD patients were analyzed for frequencies of certain health related outcomes relative to cigarette smoking. Data collected between 1985 and 2001 from natural history of ADPKD studies was analyzed to compare 350 ADPKD patients who had a history of cigarette smoking with 371 ADPKD patients who had never smoked. Details of the clinical assessment of these subjects have previously been described [2]. All diabetic patients were removed from the analysis in order to exclude risk factors associated with diabetes. Ultrasound imaging was used to assess kidney volume which was calculated for both kidneys from the anteroposterior diameter, width and length using the formula for a modified ellipsoid as previously described (2). Serum and urine chemistry data were available for these patients; however, this data set lacked information regarding smoking duration and no sera were available for further analyses. Due to the limited amount of patient data, vascular events, including aneurysm, myocardial infarction, subarachnoid hemorrhage, and symptoms of transient ischemic attack, were grouped together. In addition, data from respondents to an ADPKD survey collected between 2011 and 2012 were analyzed; this included 159 ADPKD patients who had a history of cigarette smoking and 259 who had never smoked. Responses from diabetic patients with ADPKD were removed from the analysis. Due to limited data, events were grouped into cerebrovascular events, cardiovascular events, and peripheral vascular problems. Cerebrovascular events included stroke, cerebral hemorrhage, and aneurysm. Cardiovascular events included myocardial infarction, abdominal aortic aneurysm, cardiac surgery, and angina. Peripheral vascular disease was not measured directly rather evidence of a peripheral vascular problem was assessed by the question have you ever had "a (blood) circulation problem in your legs" (pain on walking or standing or coldness). This category included sufficient data to stand as its own category. This data set had more complete smoking data than the previous one, but is limited by the fact that data is patient-reported.

\section{Assays}

Soluble human CD40 ligand (sCD40L) was assayed in forty serum samples from ADPKD patients who were matched for age, sex, and renal function (20 current smoking patients with ADPKD and 20 ADPKD patients who had never smoked). The serum level of the sCD40L was determined using a Human CD40 Ligand/TNFSF5 Quantikine enzyme-linked immunosorbent assay (ELISA) Kit (R\&D Systems, Minneapolis, MN). The lowest limit of detection for the sCD40L ELISA is $62.5 \mathrm{pg} / \mathrm{mL}$ and intra-assay and inter assay coefficient of variation $(\mathrm{CV}) \%$ of $5.4 \%$ and $6.4 \%$ respectively.

\section{Statistical analyses}

In the natural history data, all variables were checked for the distributional assumption of normality. Serum creatinine, creatinine clearance, diastolic blood pressure (DBP), systolic blood pressure (SBP), urinary protein excretion and total kidney volume (TKV) were skewed and required a natural log transformation. Log transformed variables were analyzed using traditional parametric tests. ANCOVA adjusting for age was used to compare smokers to non-smokers. The number of cardiovascular events (CVE) was treated as a count variable and Poisson Regression was applied to compare smokers to nonsmokers. Data for log transformed variables are presented as adjusted geometric means and $95 \%$ confidence interval (CI). $\mathrm{P}<0.05$ was considered significant. All analyses were performed using SAS 9.3 (Cary, NC). In the survey data set, Chi Square test of independence was used to test the distribution of categorical variables between smokers and non-smokers with ADPKD. Independent samples tests were used to test for differences in continuous variables. Kaplan-Meier Survival Analysis was used to determine if there were differences in survival curves between smokers and non-smokers using the LogRank statistic. Cox Regression was also used to adjust for age and sex. Logistic regression was used to test the association of years of smoking with binomial outcome variables including end-stage renal disease (ESRD), development of hypertension, cerebral events, cardiovascular events, and peripheral vascular problems. Logistic regression adjusted for age and sex was used to see if number of years of smoking was associated with the primary outcomes. SAS 9.3 was used for all analyses and $\mathrm{p}<0.05$ was considered significant.

\section{Results}

In the analysis of the natural history data from ADPKD studies, smokers tended to be older than non-smokers $(p=0.0083)$ (Table 1). In models adjusted for age, smokers had higher urinary protein excretion and more cardiovascular events than non-smokers. There was no statistically significant difference between body mass index (BMI) of smokers compared to non-smokers. Smokers had an average BMI of $26.233 \pm 5.358$ and non-smokers had an average BMI of $26.433 \pm$ 5.684 .

\begin{tabular}{|l|l|l|l|}
\hline \multirow{2}{*}{ Age } & Smokers & Non-Smokers & \multirow{2}{*}{ P-value } \\
\cline { 2 - 4 } & $\mathbf{( N = 3 5 0 )}$ & $\mathbf{( N = 3 7 1 )}$ & \\
\hline & $42.9 \pm 12.1$ & $40.4 \pm 13.0$ & 0.0083 \\
\hline
\end{tabular}


Citation: Brody JS, Wang W, Schrier RW, Gitomer BR (2015) Effects of Smoking on ADPKD: Frequency of Vascular Events and Concentrations of Soluble CD40 Ligand. General Med 3: 1000175. doi:10.4172/2327-5146.1000175

Page 3 of 6

\begin{tabular}{|l|l|l|l|}
\hline Sex (Males) & $150(42.9 \%)$ & $138(37.2 \%)$ & 0.1209 \\
\hline SCR & $1.44(1.37-1.53)$ & $1.49(1.41-1.57)$ & 0.473 \\
\hline CrCl & $58.45(54.84-62.31)$ & $55.81(52.52-59.31)$ & 0.3048 \\
\hline DBP (mm Hg) & $83.16(81.83-84.51)$ & $82.9(81.61-84.21)$ & 0.7832 \\
\hline SBP (mm Hg) & $129.85(128.0-131.73)$ & $130.22(128.41-132.05)$ & 0.7844 \\
\hline MA excretion & $35.14(29.13-42.39)$ & $30.41(25.69-36.0)$ & 0.2616 \\
\hline Urinary Protein Excretion & $0.18(0.16-0.20)$ & $0.16(0.14-0.17)$ & 0.037 \\
\hline Total Kidney Volume & $1212(1123-1309)$ & $1273(1184-1369)$ & 0.3661 \\
\hline Vascular Events & $0.30(0.24-0.36)$ & $0.21(0.16-0.26)$ & $0.0463^{*}$ \\
\hline ARB & $11(3.2 \%)$ & $10(2.7 \%)$ & 0.6996 \\
\hline ACE & $117(34.3 \%)$ & $142(39.0 \%)$ & 0.2634 \\
\hline Diuretics & $103(30.5 \%)$ & $93(25.5 \%)$ & 0.1401 \\
\hline Flank Pain & $151(44.0 \%)$ & $129(35.6 \%)$ & 0.0738 \\
\hline Gross Hematuria & $157(45.1 \%)$ & $142(38.7 \%)$ & 0.0678 \\
\hline Urinary Tract Infection & $216(62.6 \%)$ & $217(59.0 \%)$ & 0.3622 \\
\hline
\end{tabular}

Table 1: ADPKD Natural history study data from 1985 to 2001 Comparing Smokers Versus Non-Smokers. Data presented as least square geometric means and 95\% confidence interval or Mean \pm standard deviation or frequency (\%). ${ }^{*}$ Vascular events presented as mean and $95 \%$ confidence interval unadjusted for age. Significant when adjusted for age in Poisson Regression.

In the analysis of ADPKD survey data from 2011 and 201, there were no differences in age, distribution of gender, and number of antihypertensive medications used between smokers and non-smokers (Table 2). There were more cerebrovascular events in smokers than in non-smokers ( $\mathrm{p}=0.0235)$; however the percentage with ESRD, hypertension, cardiovascular events and peripheral vascular problems were statistically the same in both the ADPKD patients who smoked and in the non-smoking patients. Using Kaplan-Meier survival analysis, which is unadjusted, there were no significant differences in survival until onset of hypertension, cerebrovascular event, cardiovascular event, or peripheral vascular problems between nonsmokers and smokers although onset age at cerebrovascular event was nearly significant (Table 3); however, no median could be calculated. In Cox Regression adjusted for age and sex, smokers had a higher hazard for a cerebrovascular event than non-smokers (Table 4) $(\mathrm{p}=0.035)$. There was not a higher hazard for smokers than nonsmokers for ESRD, hypertension, cardiovascular events and peripheral vascular problems (Table 4). Years of smoking was associated with increased odds of having a cerebrovascular event, $\mathrm{OR}=1.04$ (1.004-1.077), $\mathrm{p}=0.030$ (Table 5). There were no significant differences in frequency of high cholesterol (Table 2) or BMI between smokers and non-smokers. Average BMI for smokers was $25.6 \pm 4.61$, and average BMI for non-smokers was $25.9 \pm 5.372$.

\begin{tabular}{|l|l|l|l|}
\hline & Non-Smokers & Smokers & \multirow{2}{*}{ P-value } \\
\cline { 2 - 4 } & $\mathbf{( N = 2 5 9 )}$ & $\mathbf{( N = 1 5 9 )}$ & 0.8214 \\
\hline Age & $51.5 \pm 13.2$ & $53.8 \pm 13.4$ & 0.1147 \\
\hline Sex (Male) & $83(32.05 \%)$ & $63(39.62 \%)$ & 0.4362 \\
\hline $\begin{array}{l}\text { Number of Anti-Hypertensive } \\
\text { Medications }\end{array}$ & $25.9 \pm 5.4$ & $25.6 \pm 4.6$ & 0.6961 \\
\hline Years Smoked & $1.32 \pm 1.05$ & $1.28 \pm 1.02$ & -- \\
\hline Packs per/day & 0 & $14.4 \pm 12.9$ & -- \\
\hline Current smoking & 0 & $1.05 \pm 0.72$ & - \\
\hline End Stage Renal Disease & Not reported & $32(20.4 \%$ & 0.3771 \\
\hline
\end{tabular}


Citation: Brody JS, Wang W, Schrier RW, Gitomer BR (2015) Effects of Smoking on ADPKD: Frequency of Vascular Events and Concentrations of Soluble CD40 Ligand. General Med 3: 1000175. doi:10.4172/2327-5146.1000175

Page 4 of 6

\begin{tabular}{|l|l|l|l|}
\hline Hypertension & $218(84.17 \%)$ & $137(86.16 \%)$ & 0.5802 \\
\hline Cerebrovascular Events & $16(6.18 \%)$ & $20(12.58 \%)$ & 0.0235 \\
\hline Cardiovascular Events & $33(13.15 \%)$ & $22(14.86 \%)$ & 0.6307 \\
\hline Peripheral Vascular Problems & $39(15.48 \%)$ & $22(14.77 \%)$ & 0.8481 \\
\hline High Cholesterol & $105(40.54 \%)$ & $79(50 \%)$ & 0.0591 \\
\hline
\end{tabular}

Table 2: Characteristics of ADPKD smokers and non-smokers collected from 2011 and 2012 surveys. Data presented as least square geometric means and $95 \%$ confidence interval or Mean \pm standard deviation or frequency (\%).

\begin{tabular}{|l|l|l|l|}
\hline & Time to onset in Non-Smokers & Time to Onset in Smokers & P-value for the Log-Rank statistic \\
\hline End Stage Renal Disease & $66(62-71)$ & 70 (60-no upper) & 0.9641 \\
\hline Hypertension & $40(35-40)$ years & $40(38-45)$ years & 0.0988 \\
\hline Cerebrovascular Events & $54.7 \pm .21$ (no median) & $63.7 \pm 0.52$ (no median) & 0.0534 \\
\hline Cardiovascular Events & $68.3 \pm 0.85$ (no median) & $68.3 \pm 1.24$ (no median) & 0.7907 \\
\hline $\begin{array}{l}\text { Peripheral Vascular } \\
\text { problems }\end{array}$ & $59.5 \pm 0.63$ (no median) & $65.6 \pm 0.98$ (no median) & 0.7675 \\
\hline
\end{tabular}

Table 3: Results of Kaplan-Meier Analysis without adjustment. Data presented as Median and 95\% confidence interval when there was no median time to survival because the majority of the sample did not reach the endpoint.

\begin{tabular}{|l|l|l|}
\hline & HR $(95 \%$ Cl) for Smoking & P-value \\
\hline End Stage Renal Disease & $1.079(7.50-1.56)$ & 0.6816 \\
\hline Hypertension & $0.891(0.71-1.121)$ & 0.3242 \\
\hline Cerebrovascular Events & $3.248(1.08-9.71)$ & 0.0353 \\
\hline Cardiovascular Events & $1.082(0.61-1.91)$ & 0.7868 \\
\hline Peripheral Vascular Problems & $0.934(0.53-1.63)$ & 0.8092 \\
\hline
\end{tabular}

Table 4: Results from Cox Regression adjusting for age and sex. Data presented as Hazard Ratio and 95\% confidence interval (CI).

\begin{tabular}{|l|l|l|}
\hline & $\begin{array}{l}\text { OR (95\% CI) for } \\
\text { Smoking }\end{array}$ & P-value \\
\hline $\begin{array}{l}\text { End Stage Renal } \\
\text { Disease }\end{array}$ & $1.004(0.976-1.032)$ & 0.0646 \\
\hline Hypertension & $0.959(0.917-1.002)$ & 0.0638 \\
\hline $\begin{array}{l}\text { Cerebrovascular } \\
\text { Events }\end{array}$ & $1.040(1.004-1.077)$ & 0.0301 \\
\hline Cardiovascular Events & $1.037(0.997-1.079)$ & 0.0667 \\
\hline $\begin{array}{l}\text { Peripheral Vascular } \\
\text { Problems }\end{array}$ & $1.023(0.990-1.058)$ & 0.1743 \\
\hline
\end{tabular}

subjects who had never smoked $(5293 \pm 3168 \mathrm{pg} / \mathrm{mL}$ vs. $3285 \pm 2169$ $\mathrm{pg} / \mathrm{mL}, \mathrm{p}=0.025$.

\section{Discussion}

There is evidence supporting the fact that the genetic defect associated with ADPKD is directly responsible for some vascular complications [22]. Moreover, smoking is a known risk factor for developing cardiovascular disease [15]. In the general population smokers have a three to four fold greater chance of having a heart attack than non-smokers [18]. As ADPKD patients are already at an increased risk for a cardiovascular event, tobacco use by ADPKD patients may pose a particular risk in this population.

In the present study, the smoker and non-smoker groups did not

Table 5: Results from Logistic Regression adjusting for age, sex, and years smoked. Data represented as Odds Ratio and 95\% confidence interval (CI)

Serum sCD40 ligand concentration was significantly higher in ADPKD patients who were current smokers compared to ADPKD differ with regards to BMI, thus, this factor would not explain any difference in frequency of vascular events or urinary protein concentration between the groups.

In a study involving male monozygotic twins, some of whom were chronic smokers while others were nonsmokers [20], plasma renin activity (PRA) was higher at rest and during exercise in the smokers 
versus the nonsmokers, and smoking is known to activate the reninangiotensin-aldosterone system (RAAS) [23,24]. Activation of the RAAS may result in blood vessel constriction and inflammation, both of which may lead to oxidative stress and tissue injury [2,25]. Early activation of the RAAS occurs in ADPKD [26] and contributes to development of oxidative stress, hypertension, and increased risk for endothelial dysfunction [27]. Smoking may add to these perturbations of the RAAS in ADPKD patients.

Proteinuria is a predictor of renal disease progression in ADPKD $[16,28]$. Therefore, higher levels of proteinuria in smokers compared to non-smokers with ADPKD may be a risk factor for kidney disease progression independent of age. Of interest, smoking has been associated with proteinuria in Japanese, middle-aged men [12].

The results from the 2011 and 2012 survey data show that ADPKD patients who are current smokers have a higher frequency of cerebrovascular events compared to ADPKD patients who have never smoked (Tables 4 and 5). Since ADPKD patients already are at a higher risk for cerebral aneurysm [13], smoking appears to elevate this risk even further. Moreover, the number of smoking years was also shown to impact hazard for developing a cerebrovascular event in the current study (Table 5). Other studies have also reported that smoking increases chances for cerebrovascular events [29-31]. High cholesterol is also a risk factor for cerebrovascular events, but analysis of our 2011 and 2012 ADPKD survey data shows that there is no statistically significant difference in cholesterol levels between smokers and nonsmokers.

ADPKD patients who currently smoke had higher serum levels of sCD40L compared to ADPKD patients who have never smoked. Evidence suggests that smoking has an effect on sCD40L [18], a molecule in the family of tumor necrosis factors that activates cellmediated immune system functions [18,32]. Acting through its membrane receptor (CD40), sCD40L increases synthesis of proinflammatory cytokines and chemokines [32]. Levels of sCD40L are associated with chronic inflammatory conditions and acute coronary disorders [32]. Higher concentrations of sCD40L are present in patients with acute myocardial infarction [18]. Tobacco smoke causes a higher activation rate in platelets, which may contribute to the higher levels of sCD40L in smokers compared to non-smokers [18]. Due to the predisposition for vascular disease in ADPKD patients [2,33], raising levels of $\mathrm{sCD} 40 \mathrm{~L}$ by smoking would increase that pre-existing risk.

There are a few limitations that should be noted in regards to the current study. There was a lack of information about number of smoking years and whether patients are current smokers in the data from Natural History studies of ADPKD. Information regarding second hand smoke exposure was also not available for any of the studied cohorts. Additionally, the small number of cardiovascular and cerebrovascular events recorded prevented each type of event from being analyzed individually. The 2011 and 2012 survey data is patient reported, and therefore lacks laboratory values. Lastly, there was no specific information about type of smoking (cigarettes, cigars or pipe) and frequency of smoking among patients whose serum was tested for sCD40L concentration.

Nevertheless, the information gathered in this study provides evidence that smoking exacerbates vascular complications associated with ADPKD, but does not show that smoking affects progression of renal disease albeit the increased proteinuria indicates increased risk. The number of patients who had reached ESRD in the current analyses was low thus, the study is underpowered to accurately assess the effect of smoking on age at ESRD onset. Since inflammation may exacerbate renal damage, increasing the body's pro-inflammatory immune responses by smoking would likely damage the kidneys at a faster rate than ADPKD would by itself.

In conclusion, it is important that physicians emphasize the inherent risks imposed by smoking in their ADPKD patients. Moreover, although the current study does not distinguish between the effects of smoke inhalation and nicotine, use of the newer smoke free cigarettes or nicotine patches may not negate the risk in this population. Future studies are needed to address this issue.

\section{References}

1. Schrier RW (2007) Diseases of the Kidney \& Urinary Tract. Lippincott Williams \& Wilkins, Philadelphia 8: 502-530.

2. Fain PR, McFann KK, Taylor MR, Tison M, Johnson AM, et al. (2005) Modifier genes play a significant role in the phenotypic expression of PKD1. Kidney Int 67: 1256-1267.

3. Persu A, Duyme M, Pirson Y, Lens XM, Messiaen T, et al. (2004) Comparison between siblings and twins supports a role for modifier genes in ADPKD. Kidney Int 66: 2132-2136.

4. Li X (2011) Epigenetics and autosomal dominant polycystic kidney disease. Biochim Biophys Acta 1812: 1213-1218.

5. Helal I, Reed B, Mettler P, Mc Fann K, Tkachenko O, et al. (2012) Prevalence of cardiovascular events in patients with autosomal dominant polycystic kidney disease. Am J Nephrol 36: 362-370.

6. Fick GM, Johnson AM, Hammond WS, Gabow PA (1995) Causes of death in autosomal dominant polycystic kidney disease. J Am Soc Nephrol 5: 2048-2056.

7. Binswanger IA, Carson EA, Krueger PM, Mueller SR, Steiner JF, et al. (2014) Prison tobacco control policies and deaths from smoking in United States prisons: population based retrospective analysis. Brit Med J 349: g4542.

8. Oncel SY, Dick DM, Maes HH (2014) Risk factors influencing smoking behavior: a Turkish twin study. Twin Res Hum Genet 17: 563-573.

9. Tárnoki DL, Tárnoki ÁD, Lázár Z, Karlinger K, Molnár AÁ, et al. (2012) [Characteristics of smoking and secondhand smoke exposure in monozygotic and dizygotic twins: results from an international twin study]. Orv Hetil 153: 1552-1559.

10. Tarnoki DL, Tarnoki AD, Littvay L, Lazar Z, Karlinger K, et al. (2014) Transmission of second-hand smoke sensitivity and smoking attitude in a family. Ann Agric Environ Med 21: 771-775.

11. Lee J, Taneja V, Vassallo R (2012) Cigarette smoking and inflammation: cellular and molecular mechanisms. J Dent Res 91: 142-149.

12. Maeda I, Hayashi T, Sato KK, Hoh H, Harita N, et al. (2011) Cigarette smoking and the association with glomerular hyperfiltration and proteinuria in healthy middle-aged men. Clin J Am Soc Nephrol 6: 2462-2469.

13. Schrier RW, Belz MM, Johnson AM, Kaheny WD, Hughes RL, et al. (2004) Repeat imaging for intracranial aneurysms in patients with autosomal dominant polycystic kidney disease with initially negative studies: a prospective ten-year follow-up. J Am Soc Nephrol 15: 1023-1028.

14. Korja M, Lehto H, Juvela S (2014) Lifelong rupture risk of intracranial aneurysms depends on risk factors: a prospective Finnish cohort study. Stroke 45: 1958-1963.

15. Rippe JM, Angelopoulos TJ (2014) Lifestyle strategies for cardiovascular risk reduction. Curr Atheroscler Rep 16: 444.

16. Chapman AB, Johnson AM, Gabow PA, Schrier RW (1994) Overt proteinuria and microalbuminuria in autosomal dominant polycystic kidney disease. J Am Soc Nephrol 5: 1349-1354. 
Citation: Brody JS, Wang W, Schrier RW, Gitomer BR (2015) Effects of Smoking on ADPKD: Frequency of Vascular Events and Concentrations of Soluble CD40 Ligand. General Med 3: 1000175. doi:10.4172/2327-5146.1000175

Page 6 of 6

17. Moua T, Zand L, Hartman RP, Hartman TE, Qin D, et al. (2014) Radiologic and clinical bronchiectasis associated with autosomal dominant polycystic kidney disease. PLoS One 9: e93674.

18. Kayrak M, Bacaksiz A, Ulgen MS, Vatankulu MA, Zengin K, et al. (2011) Plasma concentrations of soluble CD40 ligand in smokers with acute myocardial infarction: a pilot study. Heart Vessels 26: 131-137.

19. Tsaprouni LG, Yang TP, Bell J, Dick KJ, Kanoni S, et al. (2014) Cigarette smoking reduces DNA methylation levels at multiple genomic loci but the effect is partially reversible upon cessation. Epigenetics 9: 1382-1396.

20. Laustiola KE, Lassila R, Nurmi AK (1988) Enhanced activation of the renin-angiotensin-aldosterone system in chronic cigarette smokers: a study of monozygotic twin pairs discordant for smoking. Clin Pharmaco Ther 44: 426-430.

21. Tkachenko O, Helal I, Shchekochikhin D, Schrier RW (2013) ReninAngiotensin-aldosterone system in autosomal dominant polycystic kidney disease. Curr Hypertens Rev 9: 12-20.

22. Torres VE, Cai Y, Chen X, Wu GQ, Geng L, et al. (2001) Vascular expression of polycystin-2. J Am Soc Nephrol 12: 1-9.

23. Kyvelou SM, Vyssoulis GP, Karpanou EA, Adamopoulos DN, Gialernios TP, et al. (2007) Beneficial effects of angiotensin II type 1 receptor blocker antihypertensive treatment on inflammation indices: the effect of smoking. J Clin Hypertens (Greenwich) 9: 21-27.

24. García Calzado MC, García Rojas JF, Mangas Rojas A, Millán J (1990) [Tobacco and arterial pressure (II.). The acute effects on the angiotensinconverting enzyme]. An Med Interna 7: 392-395.

25. Ruiz-Ortega M, Ruperez M, Lorenzo O, Esteban V, Blanco J, et al. (2002) Angiotensin II regulates the synthesis of proinflammatory cytokines and chemokines in the kidney. Kidney Int Suppl : S12-22.
26. Harrap SB, Davies DL, Macnicol AM, Dominiczak AF, Fraser R, et al. (1991) Renal, cardiovascular and hormonal characteristics of young adults with autosomal dominant polycystic kidney disease. Kidney Int 40: 501-508.

27. Ecder $\mathrm{T}$ (2013) Cardiovascular complications in autosomal dominant polycystic kidney disease. Curr Hypertens Rev 9: 2-11.

28. Klahr S, Breyer JA, Beck GJ, Dennis VW, Hartman JA, et al. (1995) Dietary protein restriction, blood pressure control, and the progression of polycystic kidney disease. Modification of Diet in Renal Disease Study Group. J Am Soc Nephrol 5: 2037-2047.

29. Weir BK, Kongable GL, Kassell NF, Schultz JR, Truskowski LL, et al. (1998) Cigarette smoking as a cause of aneurysmal subarachnoid hemorrhage and risk for vasospasm: a report of the Cooperative Aneurysm Study. J Neurosurg 89: 405-411.

30. Matsumoto K, Akagi K, Abekura M, Ohkawa M, Tasaki O, et al. (1999) [Cigarette smoking increases the risk of developing a cerebral aneurysm and of subarachnoid hemorrhage]. No Shinkei Geka 27: 831-835.

31. Bell BA, Symon L (1979) Smoking and subarachnoid haemorrhage. Br Med J 1: 577-578.

32. Chen C, Chai H, Wang X, Jiang J, Jamaluddin MS, et al. (2008) Soluble CD40 ligand induces endothelial dysfunction in human and porcine coronary artery endothelial cells. Blood 112: 3205-3216.

33. Ecder T, Schrier RW (2009) Cardiovascular abnormalities in autosomaldominant polycystic kidney disease. Nat Rev Nephrol 5: 221-228. 